Pacific Journal of Mathematic 


\title{
A CONJECTURE AND SOME PROBLEMS ON PERMANENTS
}

\author{
G. N. DE OLIVEIRA
}

Let $A=\left[a_{i j}\right]$ denote an $n \times n$ matrix and let $E$ be the $n \times n$ identity matrix. We will designate by $\operatorname{det} A$ and perm $A$ the determinant and the permanent of $A$ respectively. The polynomial $\varphi(z)=\operatorname{det}(z E-A)$ plays a fundamental role in matrix theory. Similarly we can consider the polynomial $f(z)=\operatorname{perm}(z E-A)$ which has been object of several studies recently, particularly when $A$ is a doubly stochastic matrix. The aim of the present paper is to give some results on the existence of matrices satisfying certain conditions involving the roots of this polynomial.

Let $M_{n}$ and $\mathscr{C}_{n}$ be the regions defined as follows: $z \in M_{n}$ if and only if there exists a stochastic matrix of order $n$ with $z$ as characteristic root; $\left(z_{1}, \cdots, z_{n}\right) \in \mathscr{C}_{n}$ if and only if there exists a stochastic matrix of order $n$ whose $n$ characteristic roots are the complex numbers $z_{1}, \cdots, z_{n}$.

Similarly we define the regions $D_{n}$ and $\mathscr{D}_{n}$ respectively when 'stochastic' is replaced by 'doubly stochastic'. $M_{n}$ was determined by Karpelevic [3] but the determination of the other three regions seems to be a very difficult problem and has not yet been solved (see [7], [8], [9]).

Replacing in the definitions of $M_{n}, \mathscr{C}_{n}, D_{n}$ and $\mathscr{D}_{n}$ 'characteristic root' by 'root of the polynomial $f(z)=\operatorname{perm}(z E-A)$ ' we can define four other regions which we shall denote by $M_{n}^{*}, \mathscr{l}_{n}^{*}, D_{n}^{*}$ and $\mathscr{D}_{n}^{*}$ respectively. To our knowledge no attempt has been made to determine these regions. Their determination is likely to be a much harder problem than the determination of $M_{n}, \mathscr{C}_{n}, D_{n}$ and $\mathscr{D}_{n}$.

Some problems dealing with the characteristic values of a matrix (like some of the problems mentioned in [6]) can be replaced by similar problems dealing with the roots of

$$
f(z)=\operatorname{perm}(z E-A) .
$$

Examples: (1) find a necessary and sufficient condition for the numbers $a_{1}, \cdots, a_{n}$ and $z_{1}, \cdots, z_{n}$ to be the principal elements of a symmetric $A$ and the roots of $f(z)=\operatorname{perm}(z E-A)$ respectively; (2) find a necessary and sufficient condition for the numbers $\lambda_{1}, \cdots, \lambda_{n}$ and $z_{1}, \cdots, z_{n}$ to be the characteristic roots of an $n \times n$ matrix $A$ and the roots of $f(z)=\operatorname{perm}(z E-A)$ respectively. In the sequel we give some results on problems of this nature. 


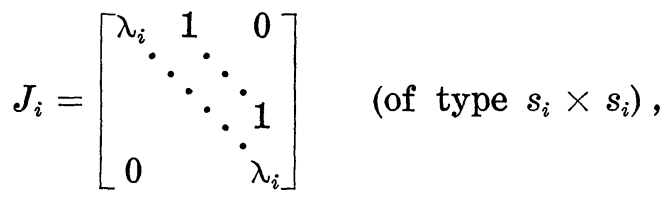

$$
\begin{aligned}
& X_{i}=\left[\begin{array}{c}
x_{1}^{i} \\
\vdots \\
x_{s_{i}}^{i}
\end{array}\right], \quad Y_{i}=\left[y_{1}^{i}, \cdots, y_{s_{i}}^{i}\right]
\end{aligned}
$$

and

$$
C=\left[\begin{array}{ccccc}
J_{1} & 0 & \cdots & 0 & X_{1} \\
0 & J_{2} & \cdots & 0 & X_{2} \\
\cdot & \cdots & \cdots & \cdot & \cdot \\
0 & 0 & \cdots & J_{m} & X_{m} \\
Y_{1} & Y_{2} & \cdots & Y_{m} & q
\end{array}\right]
$$

LEMMA. If $C$ is the matrix described above and $E$ denotes the appropriate identity matrix then

$$
\begin{aligned}
\operatorname{perm}(z E-C)= & \sum_{i=1}^{m}\left[\sum_{h=0}^{s_{i}-1} b_{i h}\left(z-\lambda_{i}\right)^{h} \prod_{\substack{j=1 \\
j \neq i}}^{m}\left(z-\lambda_{j}\right)^{s_{j}}\right] \\
& +(z-q) \prod_{j=1}^{m}\left(z-\lambda_{i}\right)^{s_{j}}
\end{aligned}
$$

where

$$
b_{i h}=(-1)^{s_{i}+h+1} \sum_{j=1}^{h+1} y_{j}^{i} x_{j+s_{i}-1-h}^{i} \quad\left(h=0, \cdots, s_{i}-1\right)
$$

Proof. Let

$$
C_{i}=\left[\begin{array}{ccccc}
J_{i} & 0 & \cdots & 0 & X_{i} \\
0 & J_{i+1} & \cdots & 0 & X_{i+1} \\
\bullet & \bullet & \cdots & \cdot & \cdot \\
0 & 0 & \cdots & J_{m} & X_{m} \\
Y_{i} & Y_{i+1} & \cdots & Y_{m} & q
\end{array}\right]
$$

Now we expand perm $\left(z E_{i}-C_{i}\right)$ (where $E_{i}$ is the identity matrix of the same order as $C_{i}$ ) in terms of its first $s_{i}$ rows. The submatrices contained in these rows with permanent nonnecessarily zero are: $z E^{(i)}-J_{i}\left(E^{(i)}\right.$ denotes the identity matrix of the same order as $\left.J_{i}\right)$ and the submatrices obtained from $z E^{(i)}-J_{i}$ by striking out the $\rho^{\text {th }}$ column $\left(\rho=1, \cdots, s_{i}\right)$ and bordering on the right hand side with the column $-X_{i}$. We denote this submatrix by $H_{\rho}$. It is not difficult to see that 


$$
\text { perm } H_{\rho}=\sum_{\tau=0}^{s_{i}-\rho}(-1)^{\tau+1} x_{\rho+\tau}^{i}\left(z-\lambda_{i}\right)^{s_{i-\tau-1}} .
$$

Let $\widetilde{H}_{\rho}$ denote the complementary submatrix of $H_{\rho}$ in $z E_{i}-C_{i}$. It can be easily seen that

$$
\operatorname{perm} \tilde{H}_{\rho}=-y_{\rho}^{i} \prod_{j=i+1}^{m}\left(z-\lambda_{j}\right)^{s_{j}}
$$

We can now write

$$
\begin{aligned}
\operatorname{perm}\left(z E_{i}-C_{i}\right)= & \sum_{\rho=1}^{s_{i}} \operatorname{perm} H_{\rho} \operatorname{perm} \widetilde{H}_{\rho} \\
& +\operatorname{perm}\left(z E^{(i)}-J_{i}\right) \operatorname{perm}\left(z E_{i+1}-C_{i+1}\right) \\
= & \sum_{\rho=1}^{s_{i}} \sum_{i=0}^{s_{i}-\rho}(-1)^{\tau} y_{\rho}^{i} x_{\rho+\tau}^{i}\left(z-\lambda_{i}\right)^{s_{i-\tau-1}} \prod_{j=i+1}^{m}\left(z-\lambda_{j}\right)^{s_{j}} \\
& +\left(z-\lambda_{i}\right)^{s} i \operatorname{perm}\left(z E_{i+1}-C_{i+1}\right) .
\end{aligned}
$$

Interchanging the order of the first two sums we get

$$
\begin{aligned}
\operatorname{perm}\left(z E_{i}-C_{i}\right)= & \sum_{i=0}^{s_{i}-1} \sum_{\rho=1}^{s_{i}-\tau}(-1)^{\tau} y_{\rho}^{i} x_{\rho+\tau}^{i}\left(z-\lambda_{i}\right)^{s_{i-\tau-1}} \prod_{j=i+1}^{m}\left(z-\lambda_{j}\right)^{s_{j}} \\
& +\left(z-\lambda_{i}\right)^{s_{i}} \operatorname{perm}\left(z E_{i+1}-C_{i+1}\right) \\
= & \sum_{h=0}^{s_{i}-1} b_{i h}\left(z-\lambda_{i}\right)^{h} \prod_{j=i+1}^{m}\left(z-\lambda_{j}\right)^{s_{j}} \\
& +\left(z-\lambda_{i}\right)^{s_{i}} \operatorname{perm}\left(z E_{i+1}-C_{i+1}\right) .
\end{aligned}
$$

We now set $i=1$, use induction, and after some manipulation we obtain the formula stated in the lemma.

We proceed to our main result.

THEOREM 1. Given any $n$ complex numbers $a_{1}, \cdots, a_{n}$ and $a$ polynomial $f(z)=z^{n}-c z^{n-1}+\cdots$, there exists a square matrix $A$ of order $n$ with $a_{1}, \cdots, a_{n}$ as principal elements and such that $f(z)=$ perm $(z E-A)$ if and only if $a_{1}+\cdots+a_{n}=c$. If this condition is satisfied and both $a_{1}, \cdots, a_{n}$ and the coefficients of $f(z)$ are real, $A$ can be chosen real.

Proof. We prove first the 'if' part. If we perform a permutation on the rows of a square matrix $A$ and then the same permutation on its columns, the roots of $f(z)=$ perm $(z E-A)$ are not altered. Hence we can, without loss of generality, take the numbers $a_{1}, \cdots, a_{n}$ in any order. Thus we will assume that the first $s_{1}$ numbers from among $a_{1}, \cdots, a_{n-1}$ have the common value $\lambda_{1}$, the following $s_{2}$ numbers have the common value $\lambda_{2}, \cdots$, the last $s_{m}$ numbers have the common value $\lambda_{m}$ and that $\lambda_{i} \neq \lambda_{j}$ for $i \neq j$. Consider now the matrix $C$ of the 
lemma with $q=a_{n}$ and all the $x_{h}^{k}=1$. We will show that we can choose $Y_{1}, \cdots, Y_{m}$ such that perm $(z E-C)=f(z)$.

Let $g(z)=\Pi_{j=1}^{m}\left(z-\lambda_{j}\right)^{s_{j}}$. Using the formula of the lemma we can write

$$
\frac{\operatorname{perm}(z E-C)}{g(z)}=\sum_{i=1}^{m} \sum_{h=0}^{s_{i}-1} \frac{b_{i h}}{\left(z-\lambda_{i}\right)^{s_{i}-h}}+z-q .
$$

Let us now resolve $f(z) / g(z)$ into partial fractions. Bearing in mind that $f(z)=z^{n}-\left(\sum_{i=1}^{n} a_{i}\right) z^{n-1}+\cdots$ we get

$$
\frac{f(z)}{g(z)}=\sum_{i=1}^{m} \sum_{h=0}^{s_{i}-1} \frac{d_{i h}}{\left(z-\lambda_{i}\right)^{s_{i}-h}}+z-q .
$$

Let us take $b_{i h}=d_{i h}$. With this choice of the $b_{i h}$ we have $f(z)=$ perm $(z E-C)$ as required. Now we compute the $y_{h}^{k}$ by $b_{i h}=$ $(-1)^{s_{i}+h+1} \sum_{j=1}^{h+1} y_{j}^{i}\left(h=0, \cdots, s_{i}-1 ; i=1, \cdots, m\right)$ which is a system of linear equations, always compatible.

If we suppose the numbers $a_{1}, \cdots, a_{n}$ as well as the coefficients of $f(z)$ real it follows from (I) that the $d_{i h}$ and therefore the $b_{i h}$ are also real. In this case $C$ can, clearly, be chosen real.

The "only if" part of the theorem is an immediate consequence of the formula

$$
\operatorname{perm}(z E-A)=z^{n}+\sum_{p=1}^{n} \sum_{1 \leqq i_{1}<\cdots<i_{p} \leqq n}(-1)^{p} \operatorname{perm} A\left(\begin{array}{l}
i_{1}, \cdots, i_{p} \\
i_{1}, \cdots, i_{p}
\end{array}\right) z^{n-p}
$$

where $A\left(\begin{array}{l}i_{1}, \cdots, i_{p} \\ i_{1}, \cdots, i_{p}\end{array}\right)$ denotes the principal submatrix of $A$ contained in the rows $i_{1}, \cdots, i_{p}$.

Concerning the problem (1) mentioned in $\S 1$ of the present paper, we have been able to prove the following partial result.

THEOREM 2. Let $a_{1}, \cdots, a_{n}$ be real numbers and suppose that there exists an index $i_{0}$ such that $i \neq j ; i, j \neq i_{0}$ implies $a_{i} \neq a_{j}$. Let $f(z)=z^{n}-c z^{n-1}+\cdots$ be a given polynomial with real coefficients such that $c=\sum_{i=1}^{n} a_{i}$.

$$
\text { If } f\left(a_{j}\right) . \prod_{\substack{i=1 \\ i \neq j, i_{0}}}^{n}\left(a_{j}-a_{i}\right) \geqq 0 \quad\left(j=1, \cdots, n ; j \neq i_{0}\right),
$$

there exists an $n \times n$ real symmetric matrix $A$ with $a_{1}, \cdots, a_{n}$ as principal elements and such that $f(z)=\operatorname{perm}(z E-A)$.

We omit the proof which follows closely the technique used in the proof of the Theorem 1 .

3. We denote by $\Omega_{n}$ the set of all doubly stochastic matrices of order $n$. When $A \in \Omega_{n}, f(z)=$ perm $(z E-A)$ enjoys some interesting 
properties as for instance: the roots of $f(z)$ lie in or on the boundary of the unit disc $|z| \leqq 1$ (see [1] and [4]). For the real roots of $f(z)$ it is known that they lie in the interval $0<x \leqq 1$. We have been led to the following

Conjecture. Let $A$ be an $n \times n$ doubly stochastic irreducible matrix. If $n$ is even, then $f(z)=$ perm $(z E-A)$ has no real roots; if $n$ is odd, then $f(z)=\operatorname{perm}(z E-A)$ has one and only one real root.

It can be seen by direct computation that the conjecture is true in the following cases:

(a) $A$ is a $2 \times 2$ real (not necessarily nonnegative) irreducible matrix all of whose row and column sums are 1.

(b) $A$ is a $3 \times 3$ real (not necessarily nonnegative) irreducible symmetric matrix all of whose row and column sums are 1.

(c) $A$ is the $n \times n$ matrix all of whose entries are equal to $1 / n$.

I wish to thank the referee for his valuable comments on a previous version of this paper.

\section{REFERENCES}

1. J. Brenner and R. Brualdi, Properties of the permanent function, Notices Amer. Math. Soc. 14 (1967), 87.

2. R. Brualdi and M. Newman, Proof of a permanental inequality, Quart. J. Math. Oxford (2) 17 (1966), 234-238.

3. F. I. Karpelevič, On the characteristic roots of matrices with nonnegative elements, Russian, Izv. Akad. Nauk SSSR, Ser. Mat. 15 (1951), 361-383.

4. M. Marcus and H. Minc, Permanents, Amer. Math. Monthly 72 (1967), 577-591.

5. L. Mirsky, Matrices with prescribed characteristic roots and diagonal elements, J. London Math. Soc. 33 (1958), 14-21.

6. - Inequalities and existence theorems in the theory of matrices, J. Math. Anal. and Appl. 9 (1964), 99-118.

7. L. Mirsky and H. Perfect, Spectral properties of doubly stochastic matrices, Monats. fur Math. 69 (1965), 35-57.

8. G. N. de Oliveira, An application of the operator $X \rightarrow A X+X B$ to the construction of nonnegative and stochastic matrices with characteristic roots related to the characteristic roots of other matrices, Rev. da. Fac. de Ciências (Lisbon) (2) 12 (1968), 15-24. 9. - On stochastic and doubly stochastic matrices, Thesis, Portuguese, English summary, Rev. da Fac. de C. da Univ. de Coimbra 41 (1968), 15-221.

10. - Matrices with prescribed characteristic polynomial and a prescribed submatrix, Pacific J. Math. 29 (1969), 653-662.

11. - Matrices with prescribed characteristic polynomial and a prescribed submatrix II, Pacific J. Math. 29 (1969), 663-668.

Received March 19, 1968.

UNIVERSIDADE DE COIMBRA

CoImbra, Portugal 



\section{PACIFIC JOURNAL OF MATHEMATICS}

\section{EDITORS}

\author{
H. SAMELSON \\ Stanford University \\ Stanford, California 94305 \\ RICHARD PIERCE \\ University of Washington \\ Seattle, Washington 98105
}

J. DugundJI

Department of Mathematics University of Southern California Los Angeles, California 90007

BASIL GORDON*

University of California

Los Angeles, California 90024

\section{ASSOCIATE EDITORS}
E. F. BECKENBACH
B. H. NEUMANN
F. WOLE
K. YOSHIDA

\section{SUPPORTING INSTITUTIONS}

\author{
UNIVERSITY OF BRITISH COLUMBIA \\ CALIFORNIA INSTITUTE OF TECHNOLOGY \\ UNIVERSITY OF CALIFORNIA \\ MONTANA STATE UNIVERSITY \\ UNIVERSITY OF NEVADA \\ NEW MEXICO STATE UNIVERSITY \\ OREGON STATE UNIVERSITY \\ UNIVERSITY OF OREGON \\ OSAKA UNIVERSITY \\ UNIVERSITY OF SOUTHERN CALIFORNIA
}

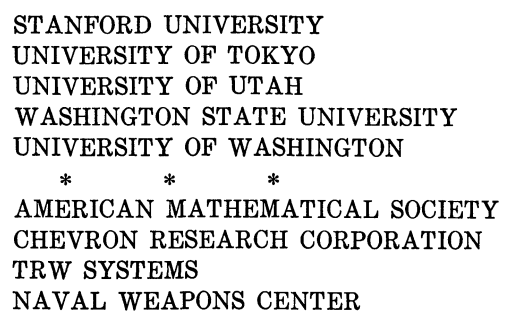

The Supporting Institutions listed above contribute to the cost of publication of this Journal, but they are not owners or publishers and have no responsibility for its content or policies.

Mathematical papers intended for publication in the Pacific Journal of Mathematics should be in typed form or offset-reproduced, (not dittoed), double spaced with large margins. Underline Greek letters in red, German in green, and script in blue. The first paragraph or two must be capable of being used separately as a synopsis of the entire paper. The editorial "we" must not be used in the synopsis, and items of the bibliography should not be cited there unless absolutely necessary, in which case they must be identified by author and Journal, rather than by item number. Manuscripts, in duplicate if possible, may be sent to any one of the four editors. Please classify according to the scheme of Math. Rev. 36, 1539-1546. All other communications to the editors should be addressed to the managing editor, Richard Arens, University of California, Los Angeles, California, 90024.

50 reprints are provided free for each article; additional copies may be obtained at cost in multiples of 50 .

The Pacific Journal of Mathematics is published monthly. Effective with Volume 16 the price per volume (3 numbers) is $\$ 8.00$; single issues, $\$ 3.00$. Special price for current issues to individual faculty members of supporting institutions and to individual members of the American Mathematical Society: $\$ 4.00$ per volume; single issues $\$ 1.50$. Back numbers are available.

Subscriptions, orders for back numbers, and changes of address should be sent to Pacific Journal of Mathematics, 103 Highland Boulevard, Berkeley, California, 94708.

PUBLISHED BY PACIFIC JOURNAL OF MATHEMATICS, A NON-PROFIT CORPORATION

Printed at Kokusai Bunken Insatsusha (International Academic Printing Co., Ltd.), 7-17, Fujimi 2-chome, Chiyoda-ku, Tokyo, Japan.

* Acting Managing Editor. 


\section{Pacific Journal of Mathematics}

\section{Vol. 32, No. $2 \quad$ February, 1970}

Harry P. Allen and Joseph Cooley Ferrar, Jordan algebras and exceptional subalgebras of the exceptional algebra $E_{6} \ldots \ldots \ldots \ldots \ldots \ldots \ldots 283$

David Wilmot Barnette and Branko Grünbaum, Preassigning the shape of a

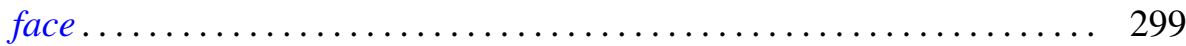

Robert Francis Craggs, Involutions of the 3-sphere which fix 2-spheres . . . . 307

David William Dean, Bor-Luh Lin and Ivan Singer, On k-shrinking and $k$-boundedly complete bases in Banach spaces ................ 323

Martin Engert, Finite dimensional translation invariant subspaces ....... 333

Kenneth Lewis Fields, On the global dimension of residue rings ......... 345

Howard Gorman, The Brandt condition and invertibility of modules ....... 351

Benjamin Rigler Halpern, A characterization of the circle and interval ..... 373

Albert Emerson Hurd, A uniqueness theorem for second order quasilinear

hyperbolic equations ............................... 415

James Frederick Hurley, Composition series in Chevalley algebras ...... 429

Meira Lavie, Disconjugacy of linear differential equations in the complex

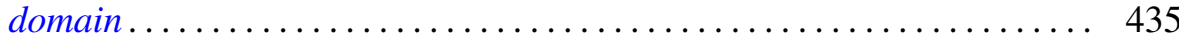

Jimmie Don Lawson, Lattices with no interval homomorphisms ......... 459

Roger McCann, A classification of center-foci ................. 467

Evelyn Rupard McMillan, On continuity conditions for functions . . . . . . . 479

Graciano de Oliveira, A conjecture and some problems on permanents .... 495

David L. Parrott and S. K. Wong, On the Higman-Sims simple group of order $44,352,000$.

Jerome L. Paul, Extending homeomorphisms ................. 517

Thomas Benny Rushing, Unknotting unions of cells .............. 521

Peter Russell, Forms of the affine line and its additive group.......... 527

Niel Shilkret, Non-Archimedean Gelfand theory ................. 541

Alfred Esperanza Tong, Diagonal submatrices of matrix maps.......... 551 